\section{mAb about FGF21}

\section{By Chris Cain, Senior Writer}

Amgen Inc. has developed an antibody that mimics fibroblast growth factor 21 and has antidiabetic effects in monkeys. ${ }^{1}$ The findings cap a year of advances that have greatly increased understanding of the protein's tissue-specific actions, and work from groups including Eli Lilly and Co. and Roche's Genentech Inc. unit is informing drug development by at least six companies.

Fibroblast growth factor 21 (FGF21) is a secreted metabolic regulator that improves insulin sensitivity, induces weight loss and lowers levels of blood glucose, triglycerides and low-density lipoproteins (LDLs) when injected in mice and monkeys.

Eli Lilly scientists were the first to describe these functions in 2005 for the protein, ${ }^{2}$ and the results prompted widespread industry interest in the therapeutic potential of targeting the FGF21 pathway to treat type 2 diabetes and obesity.

David Moller, VP of endocrine and cardiovascular research and clinical investigation at Eli Lilly, told SciBX that the potential to simultaneously treat multiple type 2 diabetes symptoms is the driving force behind pharma interest in FGF21.

"One of our major strategic goals is to find a way to treat the underlying disease pathophysiology in a way that can yield multiple beneficial effects. That's what is exciting about the FGF21 pathway-there is nothing else, practically speaking, that has the same effect."

Despite the enticing functions, multiple hurdles have slowed the development of drugs targeting the FGF21 pathway. ${ }^{3}$ Native FGF21 is not suitable as a drug because of its short half-life. Development of drugs that mimic FGF21 function has been difficult because the precise receptors, cell types and downstream mechanisms responsible for the protein's beneficial effects need to be worked out.

Junichiro Sonoda, a scientist at Genentech, told SciBX that these unanswered questions spurred intense industry and academic study of the pathway. "One thing that really excites people about FGF21 is this novel biology. Nobody knows exactly how FGF21 does all these fantastic things," he said.

A breakthrough in understanding came in 2007, when a team at The University of Texas Southwestern Medical Center identified the transmembrane protein klotho- $\beta$ (KLB) as a co-receptor required for FGF21 function. ${ }^{4}$ However, KLB pairs with multiple fibroblast growth factor receptors (FGFRs), and it was unclear which receptor complex was required for FGF21's antidiabetic effects.

Now, Amgen and Genentech have built the case that FGFR 1c isoform (FGFR1c) and KLB is the key complex and have shown antibodies designed to agonize the target can mimic FGF21's therapeutic effect. Together with academic studies describing essential pathways downstream of the receptor, a clearer picture of FGF21 function has emerged that suggests a possible path forward to tap into FGF21's therapeutic potential (see Figure 1, “FGF21 gets detailed").

\section{Getting specific}

The biotechs bookended 2012 with two separate studies published in Science Translational Medicine that described distinct FGF21-mimicking antibodies.

The first study was published in December 2011 by a Genentech team led by Sonoda. ${ }^{5}$ The researchers identified an antibody that could bind to and agonize FGFR1 (CD331) and tested it in a mouse model of diabetes. The antibody lowered blood glucose compared with IgG control for up to a month after a single injection and also caused weight loss.

The effect was likely mediated by the antibody's action on adipose tissue, as mice genetically engineered to lack the tissue did not show a reduction in blood glucose when injected with the antibody.

Sonoda told SciBX that it was a surprise that targeting FGFR1 alone could cause such significant antidiabetic effects. "We knew FGF21 acts through the liver, adipose tissue and potentially the pancreas, and FGF receptors were expressed in different patterns in each tissue. It was really a surprise that we could get this dramatic effect just by activating FGFR1 and not other FGF21 targets."

Despite the promising efficacy, Genentech is not pursuing further development of this antibody. Sonoda said the molecule binds FGFR1 but is not specific for the FGFR1c and KLB complex, and widespread activation of a major growth factor receptor could cause unpredictable side effects. Indeed, the antibody caused a reduction in serum phosphate levels in mice.

Instead of targeting FGF1R directly, Sonoda said the company would pursue the pathway by specifically targeting FGFR1c and KLB.

Less than 12 months later, a team at Amgen has published results showing the feasibility of doing exactly that. ${ }^{1}$ By screening against the FGFR1c and KLB complex, the company identified an antibody that specifically agonized FGFR1c and KLB but not FGFR1c alone. In diabetic monkeys, the antibody caused weight loss and decreased blood glucose and triglyceride levels compared with vehicle control. The antibody had no significant effect on serum phosphate levels.

To advance the argument that the FGFR1c and KLB complex in adipose tissue is responsible for these effects, the team showed that FGF21 no longer reduced blood glucose levels when administered to tissue-specific FGFR1 knockout mice. These findings were in line with a study published by Eli Lilly in August $2012 .^{6}$

"It was a surprise that this antibody could activate a complex receptor structure. This has never been seen before-there have been descriptions of agonistic antibodies, but in this case it is a receptor complex. This is a special antibody, and a major takeaway from the paper is that it opens up our eyes in terms of thinking about what 
Figure 1. FGF21 gets detailed. Researchers from Amgen Inc. and Roche's Genentech Inc. unit have separately published studies that suggest using antibodies to mimic fibroblast growth factor 21 (FGF21) action could help treat metabolic diseases, including type 2 diabetes and obesity.

In addition, separate teams at Eli Lilly and Co., Harvard Medical School and The University of Texas Southwestern

Medical Center have elucidated downstream cellular functions that help explain how FGF21 exerts its antidiabetic effects.

In adipose tissue, FGF21 binds to and activates an FGF receptor $1 \mathrm{c}$ isoform (FGFR1c) and klotho- $\beta$ (KLB) complex [a]. This triggers a signaling cascade that leads to activation of peroxisome proliferation-activated receptor- $\gamma$ (PPARG; PPAR $\gamma$ ) and PPARG coactivator $1 \alpha$ (PPARGC1A; PGC-1 $\alpha$ ) [b]. These transcriptional regulators then act to upregulate downstream targets that trigger uptake of glucose, browning of white adipose tissue, induction of thermogenesis and increases in oxidative metabolism [c].

In obese monkeys, an Amgen antibody designed to specifically activate the FGFR1c and KLB complex mimicked the antidiabetic actions of FGF21. In mice, adipocyte-specific deletion of Fgfr1c blocked the blood glucose-lowering effects of Fgf21 compared with no deletion. Together, these results suggest that targeting the FGFR1c and KLB complex in adipocytes is primarily responsible for the therapeutic action of FGF21.

antibodies can do," said Yang Li, the scientist at Amgen who led the team.

Amgen has filed a patent covering antibodies targeting KLB and FGFRs, and the company said that it is evaluating data from the current study and has not yet determined next steps.

\section{Safety signals}

Although the companies have shown proof of concept that antibodies can mimic the positive metabolic effects of FGF21, additional studies published in 2012 identified potential FGF21-mediated side effects that will need to be monitored.

Last February, a team at UT Southwestern Medical Center led by David Mangelsdorf and Steven Kliewer published papers in Cell and the Proceedings of the National Academy of Sciences that showed FGF21 can cause severe bone loss in mice. ${ }^{7,8}$ The authors traced this effect to peroxisome proliferation-activated receptor- $\gamma$ (PPARG; PPAR $\gamma$ ), which they found is activated by FGF21.

Mangelsdorf told SciBX that these safety concerns are particularly worrisome given the potential chronic administration of a diabetes drug. "This is not an acute condition; these are hormones or compounds that you will put into people for a long, long time, so the safety bar is a lot higher," he said. "FGF21 has some substantial side effects. The bone effect is really pronounced. It may also suppress female reproduction, and there are going to be others."

Mangelsdorf is chair of the Department of Pharmacology at UT Southwestern Medical Center and an investigator of the Howard Hughes Medical Institute. Kliewer is a professor of pharmacology at UT Southwestern Medical Center. He said his results argue against developing long-acting forms of FGF21.

Long-acting derivatives of FGF21 have been developed by multiple

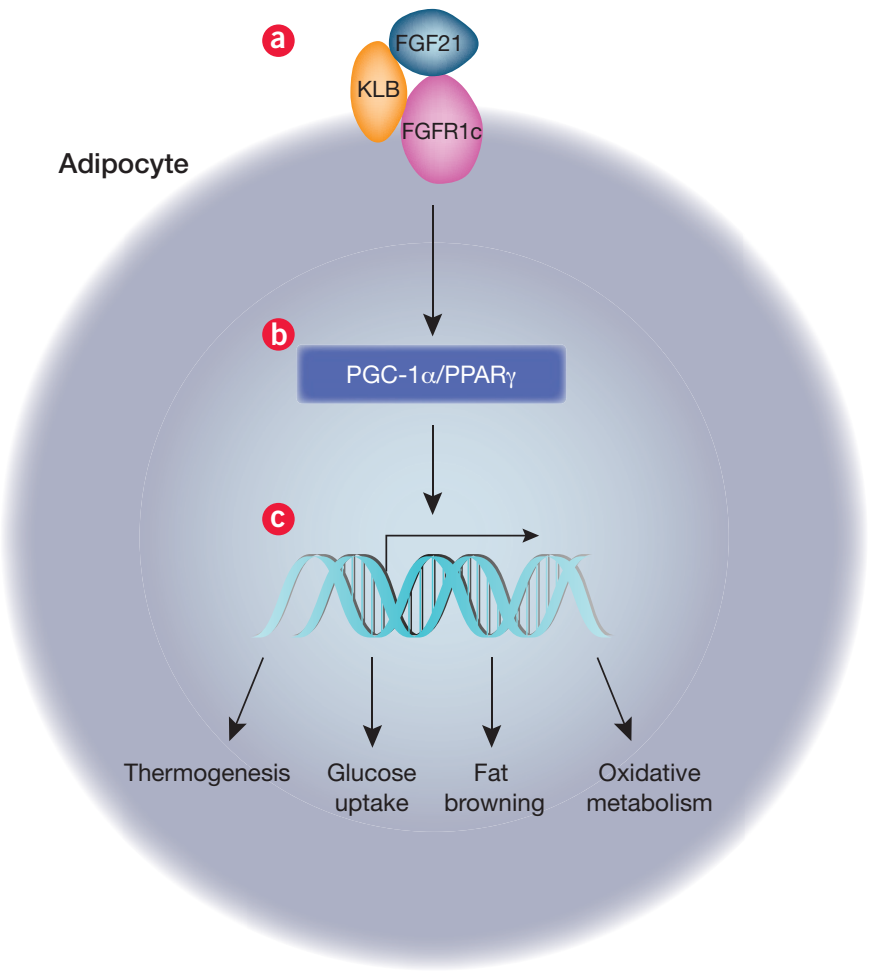

companies. Ambrx Inc. and partner Bristol-Myers Squibb Co. have ARX618, a pegylated form of FGF21, in preclinical development. ${ }^{9}$ Amgen also has published work describing a long-acting FGF2 1 analog, and Novo Nordisk A/S and Eli Lilly have filed patents covering composition of matter on FGF21 derivatives. ${ }^{10}$

Mangelsdorf said he sees more promise in the targeted approach presented by the Amgen team. "If you can target the FGF21 pathway in a tissue-specific way, I think you would have a drug," he said. He added that he would like to see the tissue-specific effect of an FGFR1c and KLB antibody examined in more detail in mouse models.

Jasbir Seehra, CSO at Ember Therapeutics Inc., agreed that tissuespecific targeting may be key to exploiting the tissue-specific effects of FGF21.

"While this may be particular to mice, the potential for bone loss in humans will need to be closely monitored in clinical studies. FGFR is expressed on cells in many tissues, but KLB shows a restricted expression pattern in the pancreas, liver and adipose tissue. In principle, an agonist antibody may be safer with limited side effects because it targets only the tissues that express KLB," he said.

Seehra said Ember is evaluating the FGF21 pathway for therapeutics that could induce brown fat-like properties, including increased glucose uptake and energy expenditure. Earlier this year, FGF21 was shown by a team at Harvard Medical School to induce the browning of white adipose tissue by activating the metabolic transcription factor PPARG coactivator $1 \alpha$ (PPARGC1A; PGC-1 $\alpha) .{ }^{11}$

Mangelsdorf said this may explain how FGF21 is exerting its positive effects on metabolism. "FGF21 is normally a starvation-induced hormone-it is a cry from the body for energy. If you look at how it works in obese individuals, it acts on adipose tissue to increase energy expenditure by stimulating glucose uptake and inducing a thermogenic response." 


\section{ANALYSIS}

Mangelsdorf's team is continuing to uncover new physiological effects of FGF21. In October 2012, his team showed that mice engineered to constitutively overexpress FGF21 lived about 33\% longer than wildtype mice, though these mice suffer bone loss and females are infertile. ${ }^{12}$ The team is now trying to understand pathways downstream of FGF21 that cause this effect on aging.

Genentech's Sonoda said that the advances made in the last year are critical for translating FGF21 to the clinic. "Every company that is working on this pathway has to be aware of these findings. It is not clear to me yet whether this approach would eliminate the safety liability of targeting the FGF21 pathway, but this is something we will need to work out with specific molecules."

Cain, C. SciBX 6(1); doi:10.1038/scibx.2013.1

Published online Jan. 10, 2013

\section{REFERENCES}

1. Foltz, I.N. et al. Sci. Transl. Med.; published online Nov. 28, 2012; doi:10.1126/scitranslmed.3004690

Contact: Yang Li, Amgen Inc., South San Francisco, Calif. e-mail: yangl@amgen.com

2. Kharitonenkov, A. et al. J. Clin. Invest. 115, 1627-1635 (2005)

3. Kharitonenkov, A. \& Larsen P. Trends Endocrinol. Metab. 22, 81-86 (2010)
4. Ogawa, Y. et al. Proc. Natl. Acad. Sci. USA 104, 7432-7437 (2007)

5. Wu, A.-L. et al. Sci. Transl. Med. 3, 113ra126 (2011)

6. Adams, A.C. et al. Mol. Metab.; published online Aug. 29, 2012; doi:10.1016/j.molmet.2012.08.007

7. Wei, W. et al. Proc. Natl. Acad. Sci. USA 109, 3143-3148 (2012)

8. Dutchak, P.A. et al. Cell 148, 556-567 (2012)

9. Mu, J. et al. Diabetes 61, 505-512 (2012)

10. Véniant, M.M. et al. PLoS ONE 7, e40164; published online July 6, 2012; doi:10.1371/journal.pone.0040164

11. Fisher, F.M. et al. Genes Dev. 26, 271-281 (2012)

12. Zhang, Y. et al. eLife 1, e00065; published online Oct. 15, 2012; doi:10.7554/eLife.00065

\section{COMPANIES AND INSTITUTIONS MENTIONED}

Ambrx Inc., La Jolla, Calif.

Amgen Inc. (NASDAQ:AMGN), Thousand Oaks, Calif. Bristol-Myers Squibb Co. (NYSE:BMY), New York, N.Y.

Eli Lilly and Co. (NYSE:LLY), Indianapolis, Ind.

Ember Therapeutics Inc., Boston, Mass.

Genentech Inc., South San Francisco, Calif.

Harvard Medical School, Boston, Mass.

Howard Hughes Medical Institute, Chevy Chase, Md.

Novo Nordisk A/S (CSE:NVO; NYSE:NVO), Bagsvaerd, Denmark Roche (SIX:ROG; OTCQX:RHHBY), Basel, Switzerland

The University of Texas Southwestern Medical Center, Dallas, Texas 